\title{
A neurologist in the COVID unit
}

\section{Reflections on a redeployment}

\author{
Stephen C. Krieger, MD \\ Neurology ${ }^{\circledR}$ 2020;95:877-880. doi:10.1212/WNL.0000000000010850
}

\section{Correspondence}

Dr. Krieger

stephen.krieger@mssm.edu

The redeployment email was unceremonious: "Your service is on one of the medicine teams. [...] Email me today with your acknowledgment."

New York City hospitals were ramping up to meet the demand of the coronavirus disease 2019 (COVID-19) surge and I would soon be redeployed to an inpatient COVID-19 unit as a medicine attending. As an outpatient multiple sclerosis (MS) specialist, with little inpatient experience for a decade, I had done no internal medicine work since my internship 18 years ago. I would not just be practicing outside of my expertise, but outside of any relevant context, placed into a supervisory role with only the most remote set of knowledge and experience. The creeping trepidation I felt before starting my internship resurfaced. What, as a neurologist, would I be able to contribute? I soaked up all I could about COVID-19-the pulmonary, renal, antimicrobial, thrombotic management. It is a cruel irony for any doctor with a touch of imposter syndrome to find oneself redeployed in a pandemic as an actual impostor.

I emailed my resident team on the eve of the redeployment. "I intend for us to be truly collaborative, with a flat hierarchy. Let's work closely together, learn from each other, and look out for each other. Let's check each other's protective equipment, and don't hesitate to call it out if something needs to be fixed or done differently. I've been a neurologist for 15 years, but you have more experience with COVID-19 than I do. If I make a mistake, or you know something I don't—which will undoubtedly be true—don't hesitate to say it."

Mount Sinai Hospital had taken a proactive approach to physician deployment, which allowed them to scale up delivery of care for inpatients and rapidly create teams, assign attendings, and disseminate training materials and protocols. ${ }^{1}$ I would be the medicine attending of record for my service, and a collaborating hospitalist had been assigned to cover several teams as a second set of eyes when needed. My team was composed of a medicine resident, a psychiatry intern, and a newly minted doctor, who had been allowed to graduate 3 months early from medical school that week to join our medical corps. I walked into the COVID-19 unit feeling like a cross between an intern and an internal medicine attending, without quite the skillset of either. This pandemic had upended the traditional academic medical hierarchy, the expertise ladder laid on its side. I arrived having read up on our COVID-19 protocols, but the residents-having had several weeks of COVID-19 experience already-knew those protocols by heart: when and how to escalate oxygenation support; which patients should get hydroxychloroquine; which ones could qualify for a clinical trial.

Our unit was a converted hematology-oncology floor, and many of our patients had a history of leukemia, lymphoma, or multiple myeloma. The unit was, however, 100\% COVID-19-positive, entailing our continuous usage of personal protective equipment (PPE) - once PPE was donned, it stayed on during all the hours spent in the "hot zone," rounding from room to room. The residents were receptive and invested; the nurse manager was welcoming, handing us a sheet with the codes to all the door locks, and daily tipoffs that donated food was on its way. There was gratitude, teamwork, and flexibility, as well as a tense but communal atmosphere of we-are-reallyin-it-now.

Quickly I had a sense of returning to the essentials of medicine internship. I felt simultaneously very close and very far from those formative experiences, of first wearing the long white coat. 
The old rounding habits came back instinctively, and the printed, stapled, folded, and copiously marked-up sign out list felt familiar in my hand. On the first day, I sought to act like an attending, and after we ran the list I said, "OK team, let's take a quick bathroom break and then suit up for rounds." And then I quietly stepped away to find someone I could surreptitiously ask, "Hey...where's the bathroom?"

I instituted daily radiology rounds for my COVID-19 medicine team, bringing some of my neurologic roots to this new environment. It felt natural to stand with my residents and compare the old and new imaging on the screens, our eyes scanning back and forth like watching a tennis match, searching for meaningful change. Instead of localizing lesions on head CTs and MRIs, though, we scrutinized chest X-rays and lung CTs and correlated these to the oxygen saturations, the ferritin levels, and procalcitonin trends that have become the new medical lingua franca of this pandemic. If, as it is said, neurology is learned by students one stroke at a time, then I learned COVID-19 one lung lobe at a time, and each new patch of ground glass became more obvious than the last.

I had expected the COVID-19 patients to all be similar, with a characteristic symptom complex, and algorithms and protocols to manage them, but they were all different. Sometimes COVID-19 was the sole concern, from mild to critical. For some patients, their unstable hematologic conditions and other comorbidities were the active issues, and the COVID-19 was almost incidental, though sufficient to get the patient admitted past the "Do not enter" sign into our COVID-19only unit. In most cases, as on neurology rounds, I found, "Are we taking good care of you?" to be the best opening line. There is so much that can be gleaned from the reply: insights into patients' mental status, their situational awareness, their health care literacy, their air hunger. Many expressed their gratitude to our team and to the nurses, but their responses most often revealed their pervasive fear, even when they seemed to be doing well. I was surprised how often I heard the words, "Am I going to die?"

Neurology prioritizes this eliciting of a patient's subjective experience of illness. Even in the unfamiliar environment of the COVID-19 unit, garbed in gowns, respirators, and face shields, understanding our patients' concerns remained essential. A former Navy officer in his 60s was transferred to our service from the intensive care unit (ICU), having been extubated after surviving fulminant acute respiratory distress syndrome from COVID-19 pneumonia. He was recovering, though his course had been complicated by a chest abscess. I was grateful that my resident could manage the chest tube and knew when to clamp it, and that he was familiar with the dosing regimen for our patient's many antibiotics, some of which had not existed when I trained. The patient's oxygen saturation was now stable, but he was also complaining of dizziness, and struggling to find the words to describe it. I smiled under my mask-finally, a conversation whose clinical subtleties felt familiar. Thinking he was searching for the word "disequilibrium," I asked him, "Does it feel like you are on a boat?" He paused and said, "You know, it's funny you should ask that, because I was in the Navy." And I said, "Yes, sir, I know - that's why I asked." He smiled broadly, closed his eyes, and nodded agreement. The sense of his being known-his life, his service, and also his symptom-solidified his rapport with his new team, a therapeutic alliance.

While helping our patients through their recovery phase was gratifying, perhaps the hardest part of taking care of people with COVID-19 was not knowing at the outset who would become critically sick and who would not. Even for internists with decades of experience, this disease has violated their assumptions. We admitted from the emergency department a Hispanic man in his mid-50s with diabetes with bilateral COVID-19 pneumonia, his oxygen saturation comfortably in the mid-90s on 2 liters. His laboratory studies, however, foretold a grim prognosis-his erythrocyte sedimentation rate and ferritin were both 15 times the upper limit of normal; his C-reactive protein was 70 times the upper limit. I was aware of early data showing that minorities were being disproportionately affected by COVID-19 and may have worse outcomes. Everything I had read about the rapid decompensation experienced by some COVID-19 patientsthe admonition to not be lulled into complacency by the appearance of high oxygen saturations at rest-seemed to apply to him. We told him that we would support his breathing, start hydroxychloroquine, infuse convalescent plasma, initiate anticoagulation, and treat his pain. He thanked us repeatedly, but with the furrowed brow and unblinking, fearful stare of someone just drafted into a war he had hoped he would not have to fight. We stepped out of his room and my resident said, "He looks pretty stable-we can probably discharge him tomorrow."

And I thought: Is he? Can we? How do we know that the day after tomorrow won't be the day that his infiltrates blossom, his oxygen saturation drops, and his trajectory takes an abysmal turn? Over the next 3 days, he defervesced, all of his inflammatory markers downtrended towards normal, and he was walking around in his room on room air. My resident had been exactly right; we discharged him home. But it gnawed at me-Was it the hydroxychloroquine that saved him? Was it the convalescent plasma? Was there a serologic marker or radiographic sign pointing to a good outcome that we could not see? In my MS practice, the treatment decisions I am accustomed to making are data-driven, cognizant of nuanced risks, and borne of shared decision-making with our patients, whom we come to know intimately. COVID-19 care proved to be, in all ways, the opposite-decisions based on minimal evidence, telegraphed interactions, and prognostic uncertainty-both for better, and for worse.

Every day there was a chance that a patient would precipitously decline. A woman in her late 40s had been hanging on tenuously with maximal oxygen support, her breathing rapid, her sentences growing shorter and more clipped. I had 
gotten to know her to the extent one can in a crisis, in between bouts of dry coughing and sharp gasps for air through the high-flow nasal cannula and nonrebreather mask, layered one on top of the other over her nose and mouth, their tubes intermingling. The next day she felt more anxious that her breathing felt tight. "I feel stiff," she said. "I can't really describe it."

My resident began to perform an arterial blood gas (ABG). The patient motioned to me to hold her hand, which was conspicuously warm. I watched him feeling for that thready, pulsing spot, as he murmured reassurances while pushing the butterfly forward. I flashed back to doing ABGs on patients with AIDS as an intern, in the midst of another, different, pandemic. How strange it initially felt to plunge the needle down into the wrist at an angle incompatible with everything I had learned about routine phlebotomy. ABGs were so much easier on those unfortunate patients, each one vented, sedated, cachectic. I would not be able to do one now. I watched my resident and thought how much harder this is on patients without a chronic disease-on someone awake, tachypneic, and plump.

In a matter of moments, in a scene that has transpired with devastatingly little variation tens of thousands of times across the United States in recent weeks, it became clear her respiratory reserve was spent, and we called a rapid response team in to intubate her. When patients are intubated in the setting of critical neurologic illness, their mental status is almost invariably already compromised. This was altogether different, the patient wide awake and terrified. I continued to hold her hand as she was prepped for intubation. There was not much more that I could do. I felt thrust back in time 20 years to being a third-year medical student, a deeply concerned interloper, not quite yet a citizen of the medical workforce. I took in details I had not noticed before-her last remaining flecks of fuchsia toenail polish, her blonde hair with perhaps a few weeks' worth of brown and gray roots at the scalp-weeks since life had been normal, weeks no one knew would turn out like this. I looked up to see what she saw, the square ceiling tiles, the curved track for the curtain, the cold lighting.

No one really tells a patient what is going on in such a moment, and if we did - amidst her gasping for air, with a team of unfamiliar faces in protective gear swarming her room like a NASCAR pit crew-how much could she understand? The patient becomes an object in need of emergency service. When the intubation team briefly stepped away and I had a moment of relative quiet in that room with her, all I could do was lean in and say, "You've been working so hard to breathe, for so long, and now we're going to bring in this machine that's going to do all that work for you, so you can finally rest. And then we'll see you on the other side." She nodded her assent, closed her eyes, and kept up her labored breathing for a few more minutes while the rapid response team took over. Will that be the last thing that she ever consciously experiences?
Was it even a fair thing for me to say, when the chances of postventilator COVID-19 survival are so dismal? I thought of the former Navy officer, who had made it through.

Serendipitously, the attending who ran the code was a redeployed neurointensivist. As our neuro-ICU had been converted, like all the other ICUs, into a COVID-19 unit, she had been deployed to run rapid response teams and to escalate the care of the sickest patients. Although we share fundamentals as neurologists - and it was a relief to see a familiar face, a kindred spirit-her proficiency extended far beyond mine into the management of critical illness, and I was deeply grateful for her expertise. Where the care I could provide to the patient as a redeployed medicine attending had ended, her care for the patient as a redeployed intensivist began. Neurologists, with diverse and essentially nonoverlapping skill sets, it turns out, could play all the necessary roles.

I expect we will look back on these weeks before approved treatments, before a COVID-19 standard of care, as a wild free-for-all, full of fumbling improvised attempts that will seem foolhardy and perhaps even tragic. I have been accumulating a steady drip of CME credits for the last 10 years, but these recent days have been a brisk education. Each week, clinical protocols and best practices sprouted new branches and pathways. Hydroxychloroquine was part of the protocol when I began my redeployment, but not when I finished. Anticoagulation protocols were intensified as data emerged about thrombotic events. On the ward, often we knew something in the afternoon that we had not known in the morning. Sometimes that information came from journals rapidly publishing new manuscripts, and other times it came right from a New York Times headline. Midway through my deployment, the media announced the first positive trial data for remdesivir. That day we donned our PPE all over again to go back to patients with whom we had discussed potentially enrolling in a remdesivir clinical trial during morning rounds, to share the breaking news, and to discuss it again. It struck me that after all the therapeutic advances we have witnessed in neurology, neurologists are well-positioned to navigate the intersection of experimentation, innovation, and patient care invoked by this pandemic.

In the final days of the deployment, my team managed to keep a couple of dozen people alive and discharged a good number of them home. I had spent 2 weeks in the hospital over a 3week span, and emerged from self-quarantine another 2 weeks later. I have thought often about the patients we discharged, the ones who did better than we could have expected, those whom we can celebrate and learn from in equal measure...but I will continue to think most about the woman we sent to the ICU, where she lay ventilated and proned. Coming back to basics to face this novel disease has highlighted for me our core attributes as neurologists, the clinical skills that we have to draw upon, our diverse talents as a field, and how deeply I respect my colleagues. 
Still, I remain uncertain how the COVID-19 pandemic will reshape neurologic subspecialty work in the future. For now, COVID-19 has rendered everything else seemingly inconsequential. What will it be like to field patient phone calls for the small, routine matters? Will this awful stretch come to seem like an aberration, or will it forever harden us to minor concerns?

Like many hospitals, ours has chosen to commemorate each COVID-19 discharge by playing a brief snippet of "Here Comes the Sun" over the hospital intercom. Hearing it play throughout the days was a reminder of each good outcome, and as the frequency increased, one could feel a sense of better days ahead. As I left my shift on the last day of my redeployment, I heard that refrain play 5 times as I walked through the hospital atrium, the lyrics reverberating off the walls from some far-away place like a malfunctioning cosmic jukebox. After these wearying weeks, it sounded like hope.

\section{Acknowledgements}

My resident team at Mount Sinai Hospital, Dr. Huazhen Chen, Dr. Anne Yeung, and Dr. Mohamed Diane for their superlative work on the COVID unit. Dr. Nada Gligorov, Dr. Megan Alcauskas, and Karin Cook for their support and thoughtful review and critique of this manuscript.

\section{Reference}

1. Kim MK, Rabinowitz LG, Nagula S, et al. A primer for clinician deployment to the medicine floors from an epicenter of COVID-19. NEJM Catalyst Epub 2020 May 4. 


\title{
Neurology
}

\author{
A neurologist in the COVID unit: Reflections on a redeployment \\ Stephen C. Krieger \\ Neurology 2020;95;877-880 Published Online before print September 14, 2020 \\ DOI 10.1212/WNL.0000000000010850
}

This information is current as of September 14, 2020

Updated Information \&
Services

Subspecialty Collections

Permissions \& Licensing

Reprints including high resolution figures, can be found at:

http://n.neurology.org/content/95/19/877.full

This article, along with others on similar topics, appears in the

following collection(s):

All Clinical Neurology

http://n.neurology.org/cgi/collection/all_clinical_neurology

\section{All Education}

http://n.neurology.org/cgi/collection/all_education

Professional conduct and ethics

http://n.neurology.org/cgi/collection/professional_conduct_and_ethics Viral infections

http://n.neurology.org/cgi/collection/viral_infections

Information about reproducing this article in parts (figures,tables) or in its entirety can be found online at:

http://www.neurology.org/about/about_the_journal\#permissions

Information about ordering reprints can be found online:

http://n.neurology.org/subscribers/advertise

Neurology ${ }^{\circledR}$ is the official journal of the American Academy of Neurology. Published continuously since 1951, it is now a weekly with 48 issues per year. Copyright @ 2020 American Academy of Neurology. All rights reserved. Print ISSN: 0028-3878. Online ISSN: 1526-632X.

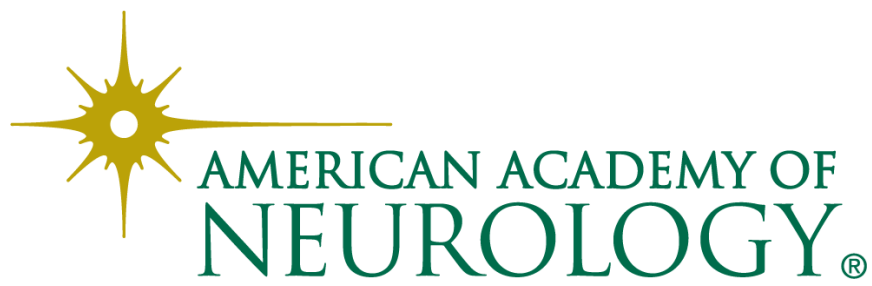

